\title{
Melatonin could be used for Treatment of COVID-19?
}

\author{
Rehab Mohamed Ali Mohamed ${ }^{1}$, Ghada Essam El-Din Amin 1,2, Salwa Mostafa Mohammad Abdel Rahman 1,3, \\ Mohamed Farouk Allam $1,4^{*}$ (C)
}

How to cite this paper: Mohamed, R. M. A., Amin, G. E. E.-D., Abdel Rahman, S. M. M., \& Allam, M. F. (2022). Melatonin could be used for Treatment of COVID-19?. Global Journal of Epidemiology and Infectious Disease, 2(1), 19-22. Retrieved from https://www.scipublications.com/journal/index.php/gjeid/article/view/188

Received: November 26, 2021 Accepted: February 21, 2022 Published: February 22, 2022

Copyright: (C) 2022 by the authors. Submitted for possible open access publication under the terms and conditions of the Creative Commons Attribution (CC BY) license (http://creativecommons.org/licenses /by/4.0/).

\author{
${ }^{1}$ Department of Family Medicine, Faculty of Medicine, Ain Shams University, Cairo, Egypt \\ ${ }^{2}$ Department of Community, Environmental and Occupational Medicine, Faculty of Medicine, Ain Shams \\ University, Cairo, Egypt \\ ${ }^{3}$ Department of Anesthesia, Intensive Care and Pain Management, Faculty of Medicine, Ain Shams Univer- \\ sity, Cairo, Egypt \\ ${ }^{4}$ Department of Preventive Medicine and Public Health, School of Medicine, University of Cordoba, Cordoba \\ 14004, Spain \\ *Correspondence: farouk.allam@med.asu.edu.eg
}

\begin{abstract}
Coronaviruses (CoVs) are a broad family of potentially serious RNA viruses that are now causing an outbreak of respiratory disease known as CoV disease 2019 (COVID-19). Melatonin is a pineal hormone that is predominantly produced and released at night from the amino acid tryptophan. Melatonin and its metabolites are also important in immunomodulation, and they have antioxidative properties due to their capacity to scavenge reactive oxygen species both directly and indirectly. COVID-19 leads to changes of altered consciousness levels in about $15 \%$ of hospitalized patients, starting from somnolence to disorientation, delirium, stupor, and coma. Melatonin can decrease the molecules that cause delirium in the elderly and central respiratory depression, such as benzodiazepines and antipsychotics. Melatonin may help alleviate infection-induced acute respiratory distress as well as its diverse effects, which include anti-inflammatory, antioxidative, and immune-enhancing properties. Its supplemental dose may be able to prevent SARS-COV-2 infections by reversing aerobic glycolysis via suppression of both HIF-1 and mTOR, allowing pyruvate dehydrogenase complex activity to be suppressed and acetyl-coenzyme A to be produced. When mitochondrion-produced and parenteral melatonin are combined, the cytokine storm is reduced, and COVID-19 infection-induced damage is alleviated. In conclusion, melatonin could have an important role in the management of COVID-19.
\end{abstract}

Keywords: Coronavirus, COVID-19, Melatonin, Management, Review.

\section{Mini Review}

Coronaviruses (CoVs) are a broad family of potentially serious RNA viruses that are now causing an outbreak of respiratory disease known as CoV disease 2019 (COVID-19). Middle East respiratory syndrome $\mathrm{CoV}$ (MERS), severe acute respiratory syndrome (SARS), and COVID-19 are serious types of illnesses that these viruses induce in humans [1]. As the structure of their spike proteins resembles that of a crown, these viruses are known as CoVs [2].

Similar to SARS-CoV, SARS-CoV-2 employs angiotensin-converting enzyme 2 (ACE2) cell receptors as a route for entrance into host cells. Various cellular proteases, such as cathepsins, transmembrane protease serine 2 (TMPRSS2), and human airway trypsin-like protease (HAT), assist the breaking of the spike protein for penetration, which is required for Corona virus entrance. A conformational shift in the spike protein promotes viral envelope fusion with the cell membrane via the endosomal route after receptor engagement. After that, viral RNA is translated, and viral mRNA directs protein 
production. Exocytosis is the process by which the virus replicates and assembles new virions, which are subsequently discharged into surrounding cells or blood vessels. A 20$\mathrm{kb}$ replica gene encodes a massive protein complex that is responsible for viral replication [3].

At the cell membrane, proteins are formed, and genomic RNA is integrated as the mature particle buds from the internal cell membrane [4]. CoV multiplication in host cells causes cellular necrosis, lysis, apoptosis and cell fusing, resulting in syncytia (Liu et al., 2001; Mossel et al., 2005)[5,6]. SARS-CoV, MERS-CoV, and SARS-CoV-2 are extremely virulent, generating a wide range of symptoms such as fever, dry cough, myalgia, tiredness, and diarrhea. Within a few days, severe disease development causes ALI, ARDS, respiratory failure, heart failure, sepsis, and sudden cardiac arrest $[5,6]$.

Edema, proteinaceous exudates with globules, patchy inflammatory cellular infiltration, and bilateral widespread alveolar injury with edema, pneumocyte desquamation, and significant hyaline membrane development are seen in pathological examinations of lungs from $\mathrm{CoV}$ patients [7]. SARS-CoV, MERS-CoV, and SARS-CoV-2 are all known to have these pathogenic characteristics. SARS-CoV-2 infections are generally significantly more severe than SARS-CoV and MERS-CoV infections in terms of symptoms and illness severity $[8,9]$.

Melatonin is a pineal hormone that is predominantly produced and released at night from the amino acid tryptophan $[10,11]$. Other tissues that synthesize it include bone marrow cells, lymphocytes, the thymus, the heart, muscle, the spleen, the liver, the stomach, the intestine, and epithelial cells [12]. Melatonin is produced by mitochondria, which also control GPCR signaling to prevent cytochrome c release [13]. Melatonin is promptly released into the cerebrospinal fluid and circulation once it is produced in the pineal gland [14]. Melatonin was first discovered as a skin-lightening agent in amphibians, but later research revealed that it influences circadian rhythms and seasonal reproduction, as well as protecting the placenta, fetus, and mother from oxidative damage caused by a variety of toxic oxidizing events associated with pregnancy [15].

Melatonin and its metabolites are also important in immunomodulation, and they have antioxidative properties due to their capacity to scavenge reactive oxygen species both directly and indirectly (ROS) [16,17]. Melatonin has now been discovered to be a very resourceful, versatile pleiotropic substance that orchestrates a wide range of physiological activities $[18,19,20]$. Specific functions are regulated by membrane-bound MT1 and MT2, as well as broadly dispersed $G$ protein-coupled receptors [21,22,23]. Other effects, such as direct free radical scavenging, appear to be receptor-independent. The MT3 receptor, a third cytosolic receptor, protects against oxidative stress by preventing quinone electron transfer processes [24].

COVID-19 leads to changes of altered consciousness levels in about $15 \%$ of hospitalized patients, starting from somnolence to disorientation, delirium, stupor, and coma. Several variables contribute to the pathogenesis of delirium, including neurotransmitter imbalance, pro-inflammatory cytokines, hypoxia, and sleep deprivation. Delirium was reported in up to $50 \%$ of hospitalized elderly patients and up to $80 \%$ of critical patients in ICU on mechanical ventilation $[25,26]$. In intensive care unit (ICU) patients, melatonin or melatonin receptor agonists (MRAs) decreased delirium and increased sleep quality $[27,28]$. Melatonin can decrease the molecules that cause delirium in the elderly and central respiratory depression, such as benzodiazepines and antipsychotics. Melatonin may help alleviate infection-induced acute respiratory distress as well as its diverse effects, which include anti-inflammatory, antioxidative, and immune-enhancing properties [29].

Its supplemental dose may be able to prevent SARS-COV-2 infections by reversing aerobic glycolysis via suppression of both HIF-1 and mTOR, allowing pyruvate dehydrogenase complex (PDC) activity to be suppressed and acetyl-coenzyme A to be produced [30]. When mitochondrion-produced and parenteral melatonin are combined, the cytokine storm is reduced, and COVID-19 infection-induced damage is alleviated [17]. Cross- 
contamination during cryopreservation, which is caused by the presence of SARS-CoV-2 on tissues, gametes, and embryos, is a major concern that must be addressed. MLT can be utilized as an anti-coronavirus agent that is not harmful to fertility [31].

In conclusion, melatonin could have an important role in the management of COVID19. New randomized controlled clinical trials to assess the effectiveness of melatonin the management of COVID-19 are strongly and urgently needed.

\section{References}

[1] Perlman S, Netland J. Coronaviruses post-SARS: update on replication and pathogenesis. Nat Rev Microbiol 2009;7:439-450.

[2] Bande F, Arshad SS, Hair Bejo M, Moeini H, Omar AR. Progress and challenges toward the development of vaccines against avian infectious bronchitis. J Immunol Res 2015:424860.

[3] Sola I, Almazan F, Zuniga S, Enjuanes L. Continuous and discontinuous RNA synthesis in coronaviruses. Annu Rev Virol 2015;2:265-88.

[4] McIntosh K, Peiris J. Coronaviruses. Clinical Virology, Third Edition, (American Society of Microbiology), 2009. pp 1155-1171.

[5] Liu C, Xu H, Liu D. Induction of caspase-dependent apoptosis in cultured cells by the avian coronavirus infectious bronchitis virus. J Virol 2001;75:6402-9.

[6] Mossel EC, Huang C, Narayanan K, Makino S, Tesh RB, Peters CJ. Exogenous ACE2 expression allows refractory cell lines to support severe acute respiratory syndrome coronavirus replication. J Virol 2005;79:3846-50.

[7] Tian X, Li C, Huang A, Xia S, Lu S, Shi Z, Lu L, Jiang S, Yang Z, Wu Y, Ying T. Potent binding of 2019 novel coronavirus spike protein by a SARS coronavirus-specific human monoclonal antibody. Emerg Microbes Infect 2020;9:382-5.

[8] Fehr AR, Perlman S. Coronaviruses: an overview of their replication and pathogenesis. Methods Mol Biol 2015;1282:1-23.

[9] Gur M, Taka E, Yilmaz SZ, Kilinc C, Aktas U, Golcuk M. Conformational transition of SARS-CoV-2 spike glycoprotein between its closed and open states. J Chem Phys 2020;153:075101.

[10] Radogna F, Diederich M, Ghibelli L. Melatonin: a pleiotropic molecule regulating inflammation. Biochem Pharmacol 2010;80:1844-52.

[11] Hardeland R, Cardinali DP, Srinivasan V, Spence DW, Brown GM, Pandi-Perumal SR. Melatonin--a pleiotropic, orchestrating regulator molecule. Prog Neurobiol 2011;93:350-84.

[12] Conti A, Conconi S, Hertens E, Skwarlo-Sonta K, Markowska M, Maestroni GJ. Evidence for melatonin synthesis in mouse and human bone marrow cells. J Pineal Res 2000;28:193-202.

[13] Suofu Y, Li W, Jean-Alphonse FG, Jia J, Khattar NK, Li J, Baranov SV, Leronni D, Mihalik AC, He Y, Cecon E. Dual role of mitochondria in producing melatonin and driving GPCR signaling to block cytochrome c release. Proc Natl Acad Sci 2017;114:E7997-E8006.

[14] Tricoire H, Locatelli A, Chemineau P, Malpaux B. Melatonin enters the cerebrospinal fluid through the pineal recess. Endocrinology 2002;143:84-90.

[15] Reiter RJ. The melatonin rhythm: both a clock and a calendar. Experientia 1993;49:654-64.

[16] Reiter RJ, Calvo JR, Karbownik M, Qi W, Tan DX. Melatonin and its relation to the immune system and inflammation. Ann N Y Acad Sci 2000;917: 376-86.

[17] Reiter RJ, Sharma R, Ma Q, Dominquez-Rodriguez A, Marik PE, Abreu-Gonzalez P. Melatonin inhibits COVID-19-induced cytokine storm by reversing aerobic glycolysis in immune cells: a mechanistic analysis. Med Drug Discov 2020;6:100044.

[18] Hardeland R. Neurobiology, pathophysiology, and treatment of melatonin deficiency and dysfunction. Sci World J 2012:640389.

[19] Acuña-Castroviejo D, Escames G, Venegas C, Díaz-Casado ME, Lima-Cabello E, López LC, Rosales-Corral S, Tan DX, Reiter RJ. Extrapineal melatonin: sources, regulation, and potential functions. Cell Mol Life Sci 2014;71:2997-3025.

[20] Hardeland R. Melatonin and the pathologies of weakened or dysregulated circadian oscillators. J Pineal Res 2017;62:e12377.

[21] Lacoste B, Angeloni D, Dominguez-Lopez S, Calderoni S, Mauro A, Fraschini F, Descarries L, Gobbi G. Anatomical and cellular localization of melatonin MT1 and MT2 receptors in the adult rat brain. J Pineal Res 2015;58:397-417.

[22] Ng KY, Leong MK, Liang H, Paxinos G. Melatonin receptors: distribution in mammalian brain and their respective putative functions. Brain Struct Funct 2017;222:2921-39.

[23] Pinato L, Ramos D, Hataka A, Rossignoli PS, Junior MD, Mazzetto MC, Campos LM. Day/night expression of MT1 and MT2 receptors in hypothalamic nuclei of the primate Sapajus apella. J Chem Neuroanat 2017;81:10-17.

[24] Nosjean O, Ferro M, Cogé F, Beauverger P, Henlin JM, Lefoulon F, Fauchère JL, Delagrange P, Canet E, Boutin JA. Identification of the melatonin-binding site MT3 as the quinone reductase 2. J Biol Chem 2000;275:31311-7.

[25] Salluh JI, Wang H, Schneider EB, Nagaraja N, Yenokyan G, Damluji A, Serafim RB, Stevens RD. Outcome of delirium in critically ill patients: systematic review and meta-analysis. BMJ 2015;350:h3129.

[26] Mao L, Jin H, Wang M, Hu Y, Chen S, He Q, Chang J, Hong C, Zhou Y, Wang D, Miao X. Neurologic manifestations of hospitalized patients with coronavirus disease 2019 in Wuhan, China. JAMA Neurol 2020;77:683-90.

[27] Zhang Q, Gao F, Zhang S, Sun W, Li Z. Prophylactic use of exogenous melatonin and melatonin receptor agonists to improve sleep and delirium in the intensive care units: a systematic review and meta-analysis of randomized controlled trials. Sleep Breath 2019;23:1059-70. 
[28] Zambrelli E, Canevini M, Gambini O, D'Agostino A. Delirium and sleep disturbances in COVID-19: a possible role for melatonin in hospitalized patients? Sleep Med 2020;70:111.

[29] Zhang R, Wang X, Ni L, Di X, Ma B, Niu S, Liu C, Reiter RJ. COVID-19: Melatonin as a potential adjuvant treatment. Life Sci 2020;250:117583.

[30] Reiter RJ, Sharma R, Ma Q, Rosales-Corral S, Acuna-Castroviejo D, Escames G. Inhibition of mitochondrial pyruvate dehydrogenase kinase: a proposed mechanism by which melatonin causes cancer cells to overcome cytosolic glycolysis, reduce tumor biomass and reverse insensitivity to chemotherapy. Melatonin Res 2019;2:105-19.

[31] Tesarik J. After corona: there is life after the pandemic. Reprod Biomed Online 2020;40:760-2. 